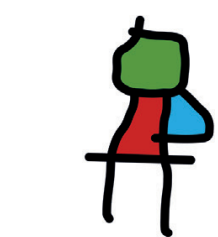

SEICAIP

\section{Allergologia et \\ immunopathologia}

Sociedad Española de Inmunología Clínica,

Alergología y Asma Pediátrica

www.all-imm.com

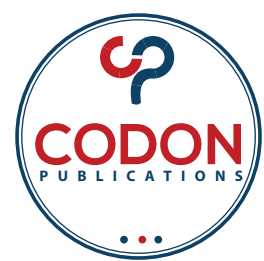

ORIGINAL ARTICLE

OPEN ACCESS ㄷㅇ(-)(2)

\title{
Rapid weight gain in early life is associated with severity of respiratory syncytial virus (RSV) bronchiolitis in children
}

\author{
You Ree Kim, Hak Kyoun Cho, Eun Hye Lee, Yong-Sung Choi, Hoi Soo Yoon, Mi Young Han, \\ Yeong Ho Rha, Hae Woon Jung*
}

Department of Pediatrics, Kyung Hee University Medical Center, Seoul, South Korea

Received 17 June 2020; Accepted 2 September 2020.

Available online 1 March 2021

\section{KEYWORDS \\ weight gain; \\ obesity; \\ bronchiolitis; \\ wheezing; \\ respiratory syncytial \\ virus}

\begin{abstract}
Objectives: This study aimed to investigate whether rapid weight gain in early life was associated with the severity of respiratory syncytial virus (RSV) bronchiolitis in children.

Methods: We retrospectively reviewed 190 patients (1-24 months) hospitalized for RSV bronchiolitis. Parameters of bronchiolitis severity were compared between rapid (change in weight $z$-score from birth $>0.67, n=65$ ) and normal weight gain groups $(n=125)$. We assessed for correlations between bronchiolitis severity and weight gain. Linear regression was performed to predict for bronchiolitis severity based on weight gain, controlling for covariates. SPSS was used for statistical analyses.

Results: The rapid weight gain group had longer mean durations of tachypnea $(2.3 \pm 2.0$ vs. $1.7 \pm 1.8$ days, $P=0.027)$, wheezing $(3.2 \pm 2.5$ vs. $1.6 \pm 1.8$ days, $P<0.001)$, and chest retractions (1.5 \pm 2.2 vs. $0.6 \pm 1.3$ days, $P=0.007)$. Correlations of weight gain with tachypnea $(r=0.146)$, wheezing $(r=0.279)$, and chest retractions $(r=0.179)$ were statistically significant. Weight gain predicted for tachypnea $(B=0.485, P=0.013)$ and wheezing $(B=0.846, P=0.001)$ durations after adjusting for covariates of severity (age, sex, current weight, RSV type, coinfection, recurrent bronchiolitis, hospital stay, fever, oxygen supplementation, maximal respiratory and heart rates, and laboratory indices).

Conclusions: Our findings suggest an association between weight gain and severity of RSV bronchiolitis in young children. Weight gain was significantly associated with the durations of tachypnea and wheezing. The trajectory of weight gain in early life may play a significant role in the clinical course of RSV bronchiolitis.
\end{abstract}

(c) 2021 Codon Publications. Published by Codon Publications.

${ }^{*}$ Corresponding author: Hae Woon Jung, MD. Department of Pediatrics, Kyung Hee University Medical Center, 23, Kyungheedae-ro, Dongdaemun-gu, Seoul 02447, South Korea. Email address: woonieya@gmail.com 


\section{Introduction}

Acute bronchiolitis is a common respiratory disorder in children under 2 years of age, caused by viral lower respiratory tract infection. Approximately $20 \%$ of children develop bronchiolitis during their first year of life, leading to hospitalizations in 2-3\%. ${ }^{1}$ Respiratory syncytial virus (RSV) is the most frequently isolated pathogen. ${ }^{2}$ RSV bronchiolitis is characterized by acute inflammation, bronchospastic contractions, and edema of the small airways with resultant tachypnea, wheezing, chest retractions, and hypoxia. The risk for severe disease is increased with male sex, prematurity, young age, chronic diseases of the lungs, heart or neuromuscular systems, and immunocompromised states. ${ }^{1,3}$

The role of obesity in the development and severity of acute respiratory diseases has been demonstrated by studies that have reported increased frequency ${ }^{4}$ and hospitalizations $^{5}$ in overweight or obese infants. Moreover, the impact of weight gain and obesity on the development and severity of childhood asthma has been explored in large cohorts. ${ }^{6-9}$ Since acute bronchiolitis is associated with recurrent wheezing and subsequent development of asthma, ${ }^{10,11}$ we postulated that there may be a similar association between obesity and the severity of acute bronchiolitis. Previous studies regarding the impact of obesity on the course of RSV bronchiolitis have been conflicting; some obese infants showed increased wheezing and fever durations ${ }^{12}$ while others showed no differences in disease severity. ${ }^{13}$ Most studies used single time-point parameters of obesity in the analyses, despite the frequent physiologic changes in weight and height percentiles in the early years. ${ }^{14} \mathrm{~A}$ recent study analyzed weight gain during the first 4 months of life as a potential risk factor for early wheezing in infants hospitalized for lower respiratory tract infections. ${ }^{15}$ That study reported increased risk for early wheezing with greater weight gain and the results suggested increased length of wheezing and hospital stay in infants with rapid weight gain. In our study, we analyzed for the change in weight z-score through two time-point measures of weight (at birth and at time of admission) and assessed for its association with the severity of RSV bronchiolitis. We aimed to investigate whether rapid gains in weight were associated with the clinical characteristics of RSV bronchiolitis in children.

\section{Materials and methods}

\section{Patients and data collection}

The medical records of patients hospitalized for acute bronchiolitis at a single tertiary hospital between January 2012 and November 2017 were reviewed. The study protocol was approved by the Institutional Review Board of our institution (IRB No. KHUH 2019-04-039). During that period, a total of 489 patients were admitted and diagnosed with RSV bronchiolitis. RSV infection was confirmed by multiplex-PCR testing of respiratory secretions by the AdvanSure $^{\text {TM }}$ SLAN-96P real-time PCR system (LG Life Science, Seoul, Korea). We included 350 patients who were between 1 and 24 months of age at diagnosis. Patients with the following characteristics were excluded: preterm birth (less than 37 gestational weeks; $n=29$ ), small for gestational age (SGA; having birthweight less than the 10th percentile for age and sex, $n=36$ ), missing birth records ( $n$ =93), suspected of asthma $(n=1)$, or having prolonged hospitalization for an unrelated surgery $(n=1)$, leaving a total of 190 patients in the final analysis. The included patients did not have any underlying chronic diseases of the cardiovascular, pulmonary, or neuromuscular systems. The patients received inpatient care at the general ward and no patients required transfers to the intensive care unit during their admission.

Birthweight data and anthropometric measures at the time of diagnosis were collected, with calculation of the respective age- and sex-specific z-scores of weight and height according to the national growth charts ${ }^{16}$ that provide information of weight and height distributions at every month from birth to 18 years of age. The amount of weight gain was determined by calculating the change in weight z-score from birth to the time of diagnosis (weight z-score at diagnosis - birthweight z-score). Rapid weight gain was defined as a change in weight z-score greater than 0.67 , which represents the crossing of at least one of the centile lines on a standard growth chart. ${ }^{17}$ Patients with weight z-score changes $>0.67$ were classified as having rapid weight gain (65 patients), while those with changes $\leq 0.67$ were classified as having normal gains in weight (125 patients).

To evaluate the severity of disease, the durations of hospital stay, fever, tachypnea, wheezing, chest retractions, oxygen supplementation, and the maximal respiratory and heart rates were reviewed. Laboratory data including white blood cell count, eosinophil count, blood urea nitrogen, uric acid, C-reactive protein, venous gas analysis of $\mathrm{pH}$, and partial pressures of oxygen and carbon dioxide were collected. Covariates that could affect the severity of RSV bronchiolitis including age, sex, RSV type, recurrent bronchiolitis, coinfection with other viral pathogens, use of antibiotics, and use of inhaled bronchodilators for treatment were also reviewed.

\section{Statistical analysis}

SPSS for Windows (version 19.0, IBM SPSS Co., NY, USA) was used for data management and analyses. Categorical variables were described by frequencies and percentages. Continuous variables were tested for normal distribution. Variables with non-normal distribution were described by the median (interquartile range) whereas continuous variables with normal distributions were described using the mean (standard deviation, SD). Differences in demographics, clinical characteristics, and severity between the two groups according to the rapidity of weight gain, were analyzed using the chi-squared test (for categorical variables), Mann-Whitney U-test (for variables with non-normal distribution), or the Student t-test (for variables with normal distribution). To measure the strength and the direction of the associations between the change in weight z-score and parameters of RSV bronchiolitis severity, Spearman's rank correlation and Pearson correlations tests were conducted. Simple and multiple linear regression analyses were conducted to predict for RSV severity (durations of tachypnea, wheezing, and chest retractions) based on weight gain, while controlling for covariates of RSV bronchiolitis severity 
(age, sex, current weight, RSV type, coinfection, recurrent bronchiolitis, hospital stay, fever, oxygen supplementation, maximal respiratory and heart rates, and laboratory indices). $P$-values $\leq 0.05$ were considered statistically significant.

\section{Results}

\section{Clinical characteristics of the patients}

Sixty-five patients showed rapid weight gain, while 125 patients showed normal changes in weight z-scores (Table 1). There was a greater percentage of male patients in the rapid weight gain group. Those with rapid weight gain also had a history of shorter gestational age and smaller birthweights.

At the time of admission for RSV bronchiolitis, the rapid weight gain group showed greater height and weight $z$-scores than the normal weight gain group. The median change in weight z-scores from birth to the time of admission was 1.26 for the rapid weight gain group and -0.1 for the normal weight gain group. There were no differences between the two groups in regard to the type of RSV infection or the presence of coinfection with other viral agents.

\section{Differences in clinical and laboratory parameters of RSV severity according to weight gain}

When the clinical parameters of RSV severity were compared between the normal and rapid weight gain groups
(Table 2), there were statistically significant differences in the means of the durations of tachypnea, wheezing, and chest retractions. The mean durations of tachypnea, wheezing, and chest retractions were significantly longer in the rapid weight gain group as compared to the respective mean durations of the normal weight gain group. We did not find statistically significant differences in the mean durations of fever, hospitalization, and oxygen supplementation between the two groups. We also did not find statistically significant differences in the means of the maximal respiratory and pulse rates observed during the admission. There were no statistically significant differences in the percentage of patients who were administered antibiotics or inhaled bronchodilators between the two weight gain groups. There were no statistically significant differences in the means of the assessed laboratory parameters between the two groups.

The increases in the durations of tachypnea, wheezing, and chest retractions with greater weight gain (as a continuous variable) were confirmed by correlation analyses. The durations of tachypnea $(r=0.146)$, wheezing $(r=0.279)$, and chest retractions $(r=0.179)$ were positively correlated with the change in weight z-score (Table 3). Male sex also correlated with increased change in weight z-score from birth to admission. The durations of wheezing and chest retractions, as well as male sex, were also positively correlated with the weight $z$-score at the time of admission. Both the lengths (in days) of the hospital stay and oxygen supplementation were not significantly associated with the degree of weight gain from birth or with the degree of obesity at the time of admission.

Table 1 Clinical characteristics and anthropometric measurements.

\begin{tabular}{|c|c|c|c|}
\hline & $\begin{array}{c}\text { All } \\
(n=190)\end{array}$ & $\begin{array}{l}\text { Normal weight gain group } \\
\qquad(\mathrm{n}=125)\end{array}$ & $\begin{array}{l}\text { Rapid weight gain group } \\
\qquad(\mathrm{n}=65)\end{array}$ \\
\hline \multicolumn{4}{|l|}{ At birth } \\
\hline Gestational age - weeks & $39.0(38.0-40.0)$ & $39.2(38.2-40.0)$ & $38.6(38.0-39.4)^{*}$ \\
\hline \multicolumn{4}{|l|}{ Sex - no. (\%) } \\
\hline Male & $112(58.9)$ & $63(50.4)$ & $49(75.3)^{* *}$ \\
\hline Female & $78(41.0)$ & $62(49.6)$ & $16(24.6)^{* *}$ \\
\hline Birthweight - kg & $3.30(3.09-3.50)$ & $3.34(3.12-3.51)$ & $3.25(2.98-3.45)^{*}$ \\
\hline Birthweight - z-score & $-0.14 \pm 0.60$ & $-0.04 \pm 0.57$ & $-0.33 \pm 0.61^{*}$ \\
\hline \multicolumn{4}{|l|}{ At admission } \\
\hline Age - months & $5.3(2.5-12.6)$ & $5.3(2.2-14.0)$ & $5.6(3.4-10.3)$ \\
\hline Height - z-score & $0.12(-0.59-0.74)$ & $-0.06(-0.81-0.4)$ & $0.47(-0.03-1.03)^{* *}$ \\
\hline Weight - z-score & $0.13 \pm 1.04$ & $-0.32 \pm 0.85$ & $1.03 \pm 0.77^{* *}$ \\
\hline Change in weight - z-score & $0.26(-0.34-0.91)$ & $-0.1(-0.63-0.23)$ & $1.26(0.91-1.56)^{* *}$ \\
\hline \multicolumn{4}{|l|}{ RSV type - no. (\%) } \\
\hline A & $115(60.5)$ & $78(62.4)$ & 37 (56.9) \\
\hline B & $75(39.5)$ & $47(37.6)$ & $28(43.1)$ \\
\hline \multicolumn{4}{|l|}{ Coinfection - no. (\%) } \\
\hline Yes & $72(37.8)$ & $45(36.0)$ & $27(41.5)$ \\
\hline No & $118(62.1)$ & $80(64.0)$ & $38(58.5)$ \\
\hline
\end{tabular}

Data expressed as mean \pm standard deviation or median (interquartile range).

RSV: respiratory syncytial virus.

${ }^{*} P<0.05$ compared to the normal weight group.

${ }^{* *} P<0.001$ compared to the normal weight group. 
Table 2 Clinical and laboratory characteristics according to weight gain.

\begin{tabular}{|c|c|c|c|}
\hline & $\begin{array}{c}\text { Total } \\
(\mathrm{n}=190)\end{array}$ & $\begin{array}{l}\text { Normal weight gain group } \\
\qquad(\mathrm{n}=125)\end{array}$ & $\begin{array}{l}\text { Rapid weight gain group } \\
\qquad(\mathrm{n}=65)\end{array}$ \\
\hline \multicolumn{4}{|l|}{ Clinical characteristics } \\
\hline Hospital stay - days & $5.0(4.0-7.0)$ & $5.0(4.0-6.0)$ & $5.0(4.0-7.0)$ \\
\hline \multicolumn{4}{|l|}{ Fever - days } \\
\hline Present - No. (\%) & $128(67.4 \%)$ & $83(66.4 \%)$ & $45(69.2 \%)$ \\
\hline Duration - days & $2.3 \pm 2.3$ & $2.3 \pm 2.2$ & $2.3 \pm 2.3$ \\
\hline \multicolumn{4}{|l|}{ Tachypnea - days } \\
\hline Present - No. (\%) & $117(61.6 \%)$ & $72(57.6 \%)$ & $45(69.2 \%)$ \\
\hline Duration - days & $1.9 \pm 1.9$ & $1.7 \pm 1.8$ & $2.3 \pm 2.0^{*}$ \\
\hline \multicolumn{4}{|l|}{ Wheezing - days } \\
\hline Present - No. (\%) & $130(68.4 \%)$ & $76(60.8 \%)$ & $54(83.1 \%)^{*}$ \\
\hline Duration - days & $2.1 \pm 2.2$ & $1.6 \pm 1.8$ & $3.2 \pm 2.5^{* *}$ \\
\hline \multicolumn{4}{|l|}{ Retractions - days } \\
\hline Present - No. (\%) & $73(38.4 \%)$ & $41(32.8 \%)$ & $32(49.2 \%)^{*}$ \\
\hline Duration - days & $0.9 \pm 1.7$ & $0.6 \pm 1.3$ & $1.5 \pm 2.3^{*}$ \\
\hline \multicolumn{4}{|l|}{$\mathrm{O}_{2}$ supply - days } \\
\hline Present - No. (\%) & $41(21.6 \%)$ & $24(19.2 \%)$ & $17(26.2 \%)$ \\
\hline Duration - days & $0.8 \pm 1.7$ & $0.7 \pm 1.6$ & $0.9 \pm 1.9$ \\
\hline Maximal heart rate - beats per minute & $140(132-156)$ & $140(132-156)$ & $140(132-150)$ \\
\hline Maximal respiratory rate - beats per minute & $42(36-48)$ & $42(36-49)$ & $42(36-48)$ \\
\hline Use of antibiotics - No. (\%) & $82(43.2 \%)$ & 57 (46.5\%) & $25(38.5 \%)$ \\
\hline Use of inhaled bronchodilators - No. (\%) & $185(97.4 \%)$ & $121(96.8 \%)$ & $64(98.5 \%)$ \\
\hline \multicolumn{4}{|l|}{ Laboratory characteristics } \\
\hline WBC - count $/ \mu \mathrm{L}$ & $10,045(7980-12,310)$ & $10,050(7990-12,650)$ & $9950(7980-11,570)$ \\
\hline Eosinophil - \% & $1.4(0.7-3.0)$ & $2.0(0.8-3.0)$ & $1.0(0.5-2.1)$ \\
\hline $\mathrm{CRP}-\mathrm{mg} / \mathrm{dL}$ & $0.5(0.3-1.0)$ & $0.4(0.3-0.9)$ & $0.5(0.3-1.3)$ \\
\hline BUN - mg/dL & $8(6-10)$ & $8(6-10)$ & $8(7.0-10)$ \\
\hline $\mathrm{pH}$ & $7.39(7.36-7.42)$ & $7.40(7.35-7.43)$ & $7.39(7.37-7.41)$ \\
\hline $\mathrm{pCO}_{2}-\mathrm{mmHg}$ & $36(32-42)$ & $36(32-43)$ & $36(32-41)$ \\
\hline $\mathrm{pO}_{2}-\mathrm{mmHg}$ & $45(39-53)$ & $46(40-54)$ & $44(38-53)$ \\
\hline
\end{tabular}

Data expressed as mean \pm standard deviation or median (interquartile range).

BUN: blood urea nitrogen; $\mathrm{CRP}$ : C-reactive protein; $\mathrm{pCO}_{2}$ : partial pressure of carbon dioxide; $\mathrm{pO}_{2}$ : partial pressure of oxygen; WBC: white blood cell.

${ }^{*} P<0.05$ compared to the normal weight group.

** $P<0.001$ compared to the normal weight group.

\section{Regression analyses of indicators of RSV severity}

After adjusting for covariates of RSV severity and the weight $z$-score at admission, both wheezing and tachypnea durations were associated with the amount of weight gain (Table 4). The change in z-score from birth to the time of admission, rather than the current weight z-score at admission, significantly predicted for increased durations of tachypnea and wheezing in RSV bronchiolitis, with adjustment for covariates of RSV severity.

\section{Discussion}

Signs of RSV bronchiolitis were more severe in children with greater weight gain between birth and admission. Children who showed increases in weight $z$-score $>0.67$ had significantly longer durations of tachypnea, wheezing, and retractions when admitted for RSV bronchiolitis. The gain in weight z-score was positively correlated to the durations of tachypnea, wheezing, and retractions. The associations between weight gain and the durations of tachypnea and wheezing remained significant even after adjusting for covariates of RSV severity and the weight z-score at the time of admission.

Previous studies have shown that an obesity ratio [(observed body weight - standard body weight for age and sex)/standard body weight for age and sex $\times 100$ ] greater than 6 at the time of RSV infection resulted in increased durations of wheezing, fever, and intravenous infusions. ${ }^{12}$ Similarly, being overweight (weight-for-length $>110 \%$ ) at 1.5 years of age was associated with recurrent post-bronchiolitis wheezing. ${ }^{18}$ In contrast, being overweight or obese according to weight-for-length z-scores, was not significantly associated with clinical characteristics of viral acute bronchiolitis. ${ }^{13}$ These results may differ because of the varying parameters used to define obesity in young children under 2 years of age. Owing to the lack of specific 
Table 3 Correlation analysis between weight z-score and clinical parameters of RSV severity.

\begin{tabular}{lcc}
\hline & $\begin{array}{c}\text { Change in } \\
\text { weight z-score } \\
r\end{array}$ & $\begin{array}{c}\text { Weight z-score at } \\
\text { admission }\end{array}$ \\
\hline Age & 0.097 & 0.075 \\
Sex & $-0.432^{*}$ & $-0.335^{*}$ \\
RSV type & 0.060 & 0.119 \\
Coinfection & 0.179 & 0.160 \\
Hospital stay & 0.004 & 0.060 \\
Fever & -0.007 & 0.008 \\
Tachypnea & $0.146^{*}$ & 0.113 \\
Wheezing & $0.279^{* *}$ & $0.210^{*}$ \\
Retractions & $0.179^{*}$ & $0.182^{*}$ \\
$\mathrm{O}_{2}$ supply & 0.030 & 0.054 \\
Maximal heart rate & -0.047 & -0.057 \\
Maximal respiratory rate & -0.002 & 0.071 \\
Use of antibiotics & -0.083 & -0.049 \\
Use of inhaled & 0.022 & 0.100 \\
$\quad$ bronchodilators & & \\
WBC & -0.033 & 0.010 \\
Eosinophil & -0.100 & -0.063 \\
CRP & 0.091 & 0.025 \\
BUN & 0.015 & 0.067 \\
pH & -0.013 & -0.007 \\
pCO & -0.040 & -0.038 \\
pO ${ }_{2}$ & -0.079 & -0.127 \\
\hline & &
\end{tabular}

BUN: blood urea nitrogen; CRP: C-reactive protein; $\mathrm{pCO}_{2}$ : partial pressure of carbon dioxide; $\mathrm{pO}_{2}$ : partial pressure of oxygen; WBC: white blood cell.

${ }^{*} P<0.05$.

**P $<0.001$.

criteria, these studies used various measures of obesity including the obesity ratio, weight-for-length, or body mass index. The use of supine length in weight-for-length or BMI parameters may be prone to error in this age group, ${ }^{19}$ and less accurate than weight measures. ${ }^{20,21}$ Moreover, measures to determine weight status at a single time-point may be less accurate, since physiologic variations in height and weight are at their greatest during the first 2 years of life. Nearly $40 \%$ of children cross two centile lines on a standard weight-for-age growth chart in the first 6 months of life, with an additional 6 to $15 \%$ of children crossing two centile lines thereafter from 6 months to 2 years of age. ${ }^{14}$ While the single time-point weight-for-age z-score at the time of admission showed positive correlations with durations of wheezing and retractions in our study, the associations were not significant after adjustment for covariates of bronchiolitis severity.

The weight gain, calculated from two-point measures of weight, showed a greater association with the severity of RSV bronchiolitis. The association between greater weight gain and bronchiolitis severity was significant even after adjusting for the current weight z-score at admission and other covariates of severity. The change in weight z-score may be an effective screening tool for early identification of infants at risk for subsequent obesity ${ }^{22}$ and has been shown to be a better predictor of childhood obesity compared to changes in infant length, BMI, and the ponderal index. ${ }^{23}$ Despite this, there have not been many studies that examined the effect of postnatal weight gain on the severity of acute bronchiolitis. One recent study analyzed for associations between weight gain and early wheezing in infants hospitalized for lower respiratory tract infections. ${ }^{15}$ The study found that the presence of wheezing was higher in the group of infants with rapid weight gain during the first four postnatal months. The mean lengths of wheezing duration and hospital stay were also significantly longer in the group with rapid weight gain and this suggests a possible role of weight gain as a risk factor for early wheezing in infants. One other previous study noted a positive correlation between weight gain and post-bronchiolitis wheezing, but the association was significant only in children whose birthweights were greater than 4000 g. ${ }^{18}$ While our results also show a positive correlation between weight gain and wheezing duration, our results differ in that children with rapid weight gain had slightly lower, albeit normal, birthweights when compared to those with normal gains in weight. Low birthweight in itself has been reported as a risk factor for the development and increased severity of RSV bronchiolitis. ${ }^{24,25}$ The degree of weight gain may be a contributing factor since children with low birthweights have a tendency towards accelerated weight gain in early life due to catch up growth. ${ }^{17,26}$ Inflammation may be another contributing factor since low birthweight infants were found to have higher

Table 4 Multivariate regression analyses of parameters of RSV severity.

\begin{tabular}{|c|c|c|c|c|c|c|}
\hline & \multicolumn{2}{|c|}{ Tachypnea duration } & \multicolumn{2}{|c|}{ Wheezing duration } & \multicolumn{2}{|c|}{ Retractions duration } \\
\hline & $\beta$ & $P$-value & $\beta$ & $P$-value & $\beta$ & $P$-value \\
\hline Age & 0.121 & 0.001 & 0.003 & 0.921 & -0.011 & 0.669 \\
\hline Sex & 0.217 & 0.343 & -0.152 & 0.599 & -0.181 & 0.469 \\
\hline Weight z-score at admission & -0.248 & 0.202 & -0.381 & 0.077 & 0.033 & 0.894 \\
\hline Change in weight z-score & 0.485 & 0.013 & 0.846 & 0.001 & 0.214 & 0.180 \\
\hline
\end{tabular}

Adjusted for RSV type, coinfection, recurrent bronchiolitis, hospital stay, fever duration, $\mathrm{O}_{2}$ supply duration, maximal respiratory rate, maximal heart rate, eosinophil counts, C-reactive protein (CRP), blood urea nitrogen (BUN), and partial pressure of carbon dioxide $\left(\mathrm{pCO}_{2}\right)$. 
inflammatory marker levels (IL-6) and more severe bronchiolitis symptoms. ${ }^{27}$ Further studies are needed to elucidate the possible interactions between low birthweight, increased weight gain, inflammatory markers, and severity of RSV bronchiolitis.

Our study suggests an association between accelerated weight gain in early life and the severity of RSV bronchiolitis. The relationship between early life weight gain trajectories with the development of diseases in later life is well established in the developmental origins of health and disease (DOHAD) hypothesis. This hypothesis implicates that environmental stimuli during critical periods of early growth and development result in permanent changes that determine susceptibility to diseases in later life, through remodeling of tissues, resetting of endocrine axes, alterations in gene expression and epigenetics. ${ }^{28}$ Obesity, hypertension, cardiovascular disease, type 2 diabetes, and stroke are diseases well known to be affected by growth and nutritional status in early life. ${ }^{17,29}$ Respiratory diseases have also been studied in this perspective for associations to early life weight gain. In particular, increased susceptibility and severity of asthma in later childhood has been associated with greater weight gain in early life. ${ }^{6-9}$ Since acute bronchiolitis has been associated with recurrent wheezing and subsequent development of asthma, ${ }^{10,11}$ the mechanisms underlying their respective associations to early life weight gain may be similar.

The mechanisms whereby rapid weight gain or obesity exert effects on the severity of respiratory disease may involve changes in pulmonary mechanics and the perpetuation of chronic, low-grade, systemic inflammation. In a meta-analysis of the effects of obesity on lung function, being overweight or obese was shown to be detrimental to lung function across age groups. ${ }^{30}$ Specifically, obese children showed a pronounced decline in forced expiratory volume in 1 second (FEV1)/forced vital capacity (FVC) and forced expiratory flow between 25 and 75\% $\left(\mathrm{FEF}_{25-75}\right)$ of the FVC. ${ }^{30,31}$ One study of the effects of early weight gain pattern and lung function at 5 years of age showed significant decreases in FEV1 and $\mathrm{FEF}_{25-75}$ for every one-point increase in weight z-score. ${ }^{9}$ Such spirometric changes suggest the presence of airflow obstruction in obesity, which can manifest clinically as wheezing, tachypnea, and chest retractions. However, caution is needed in interpreting the finding of decreased FEV1/FVC in children with obesity, since there is evidence that decreased FEV1/FVC in obesity is related to an increase in FVC, rather than a decrease in FEV1. ${ }^{32}$ These findings suggest the presence of dysanapsis, a state of normal flow in large lungs rather than actual airflow obstruction, in overweight and obese children. The presence of dysanapsis has been associated with worse clinical outcomes in children with asthma. Further studies are needed to evaluate such changes in children with rapid weight gain, and its role in affecting the severity of RSV bronchiolitis. Furthermore, chronic, low-grade, systemic inflammation in obesity may contribute to impaired immune responses in obese individuals by dysregulated production of pro-inflammatory adipocytokines. ${ }^{33}$ Production of pro-inflammatory mediators including leptin, interleukin-6 (IL-6), tumor necrosis factor- $a$ (TNF-a), monocyte chemoattractant protein-1 (MCP-1), and resistin are increased while anti-inflammatory mediators including adiponectin and interleukin-10 are decreased in obesity. ${ }^{34}$ Such changes may result in the modulation of immune responses of polymorphonuclear neutrophils, T-lymphocytes, and activation of monocytes/macrophages. ${ }^{35}$ Increased leptin ${ }^{36}$ and leptin/ adiponectin ratio $^{37}$ have been reported in infants with RSV bronchiolitis. Leptin can upregulate leukotriene biosynthesis and induce pulmonary inflammation. ${ }^{38}$ Furthermore, murine models of adiponectin deficiency have shown evidence of pulmonary inflammation and remodeling. ${ }^{39}$ Further studies that can elucidate differences in pulmonary mechanics and adipocytokine levels according to obesity or weight gain in the clinical setting of RSV bronchiolitis are warranted.

This study is limited by the relatively small sample size and statistical power that cannot be generalized considering the prevalence of RSV bronchiolitis. The data were generated by a retrospective review and the analysis was correlational in design. The assessment of bronchiolitis severity was based on subjective physical examinations conducted by several physicians. Scoring systems have been validated for use in assessing the severity of acute bronchiolitis in children, ${ }^{40}$ however, due to the retrospective design of the study, we did not have all the necessary information to use those scoring systems. As such, we assessed for bronchiolitis severity by using individual parameters such as tachypnea, wheezing, and chest retractions. Prospective studies that could assess the severity more objectively by use of validated scoring systems are warranted. In addition, important confounding factors including the type of feeding (breast or formula) and household smoke exposures could not be obtained retrospectively. We did not have information about personal or family history of atopic disease. Mechanistic variables including tests of lung function or related inflammatory or anti-inflammatory adipocytokines, which could provide insight into how weight gain could influence the symptoms of RSV bronchiolitis, were not available for analysis. However, this study adds insights into the relationship between obesity and the severity of acute respiratory diseases in children and is strengthened in its examination of weight at two time-points from birth to admission to assess for the relationship between weight gain in early life and various parameters of the severity of RSV bronchiolitis. Future prospective studies with added confounding factors and mechanistic variables are warranted to further elucidate the pathophysiology of the association between weight gain and RSV bronchiolitis.

In conclusion, our findings suggest an association between weight gain from birth and the severity of symptoms and signs in infants and young children with RSV bronchiolitis. The gains in weight z-score were significantly associated with the durations of tachypnea and wheezing, suggesting that the trajectory of weight gain in early life may play an important role in the clinical course of RSV bronchiolitis in infants and young children.

\section{Funding statement}

This research did not receive any specific grant from funding agencies in the public, commercial, or not-for-profit sectors. 


\section{Conflicts of interest}

The authors have no conflicts of interest to declare.

\section{References}

1. Øymar K, Skjerven HO, Mikalsen IB. Acute bronchiolitis in infants, a review. Scand J Trauma Resusc Emerg Med. 2014;22(1):23. https://doi.org/10.1186/1757-7241-22-23

2. Bueno FU, Piva JP, Garcia PC, Lago PM, Einloft PR. Outcome and characteristics of infants with acute viral bronchiolitis submitted to mechanical ventilation in a Brazilian pediatric intensive care. Rev Bras Ter Intensiva. 2009;21(2):174-182. https://doi.org/10.1590/S0103-507X2009000200010

3. Meissner HC. Viral bronchiolitis in children. N Engl J Med. 2016;374(1):62-72. https://doi.org/10.1056/NEJMra1413456

4. Tracey VV, De NC, Harper JR. Obesity and respiratory infection in infants and young children. Br Med J. 1971;1(5739): 16-18. https://doi.org/10.1136/bmj.1.5739.16

5. Shibli R, Rubin L, Akons H, Shaoul R. Morbidity of overweight (>or $=85$ th percentile) in the first 2 years of life. Pediatrics. 2008;122(2):267-272. https://doi.org/10.1542/peds.2007-2867

6. den Dekker HT, Jaddoe VWV, Reiss IK, de Jongste JC, Duijts L. Fetal and infant growth patterns and risk of lower lung function and asthma. The Generation R study. Am J Respir Crit Care Med. 2018;197(2):183-192. https://doi.org/10.1164/ rccm.201703-06310C

7. Sonnenschein-van der Voort AM, Arends LR, de Jongste JC, Annesi-Maesano I, Arshad SH, Barros H, et al. Preterm birth, infant weight gain, and childhood asthma risk: a metaanalysis of 147,000 European children. J Allergy Clin Immunol. 2014;133(5):1317-1329. https://doi.org/10.1016/j.jaci.2013.12. 1082

8. Rzehak P, Wijga AH, Keil T, Eller E, Bindslev-Jensen C, Smit HA, et al. Body mass index trajectory classes and incident asthma in childhood: results from 8 European birth cohorts - a Global Allergy and Asthma European Network initiative. J Allergy Clin Immunol. 2013;131(6):1528-1536. https:// doi.org/10.1016/j.jaci.2013.01.001

9. van der Gugten AC, Koopman M, Evelein AM, Verheij JM, Uiterwall CSPM, van der Ent CK. Rapid early weight gain is associated with wheeze and reduced lung function in childhood. Eur Respir J. 2012;39(2):403-410. https://doi. org/10.1183/09031936.00188310

10. Balekian DS, Linnemann RW, Hasegawa K, Thadhani R, Carmargo CA Jr. Cohort study of severe bronchiolitis during infancy and risk of asthma by age 5 years. J Allergy Clin Immunol Pract. 2017;5(1):92-96. https://doi.org/10.1016/j. jaip.2016.07.004

11. Carroll KN, Wu P, Gebretsadik T, Griffin MR, Dupont WD, Mitchel EF, et al. The severity-dependent relationship of infant bronchiolitis on the risk and morbidity of early childhood asthma. J Allergy Clin Immunol. 2009;123(5):1055-1061. https://doi.org/10.1016/j.jaci.2009.02.021

12. Akiyama N, Segawa T, Ida H, Mezawa H, Noya M, Tamez S, et al. Bimodal effects of obesity ratio on disease duration of respiratory syncytial virus infection in children. Allergol Int. 2011;60(3):305-308. https://doi.org/10.2332/ allergolint.10-0A-0252

13. Cha MA, Woo YR, Kim HJ, Kim MS, Ahn YH. Factors associated with obesity of acute bronchiolitis in infants: association of obesity with disease severity. Allergy Asthma Respir Dis. 2015;3(4):281-287. https://doi.org/10.4168/aard.2015.3.4.281

14. Mei Z, Grummer-Strawn LM, Thompson D, Dietz WH. Shifts in percentiles of growth during early childhood: analysis of longitudinal data from the California Child Health and Development Study. Pediatrics. 2004;113(6):e617-e627. https://doi.org/10.1542/peds.113.6.e617

15. Yin L, Song $Y$, Liu $Y$, Ye Z. A risk factor for early wheezing in infants: rapid weight gain. BMC Pediatr. 2019;19(1):352. https://doi.org/10.1186/s12887-019-1720-3

16. Moon JS, Lee SY, Nam CM, Choi JM, Choe BK, Seo JW, et al. Korean National Growth Charts: review of developmental process and an outlook. Korean J Pediatr. 2007;51:2008. https:// doi.org/10.3345/kjp.2008.51.1.1

17. Ong KK, Ahmed ML, Emmett PM, Preece MA, Dunger DB. Association between postnatal catch-up growth and obesity in childhood: prospective cohort study. BMJ. 2000;320(7240): 967-971. https://doi.org/10.1136/bmj.320.7240.967

18. Nuolivirta $K$, Koponen $P$, Helminen $M$, Korppi $M$. Weight gain in infancy and post-bronchiolitis wheezing. Acta Paediatr. 2012;101(1):38-42. https://doi.org/10.1111/j.16512227.2011.02414.x

19. Rifas-Shiman SL, Rich-Edwards JW, Scanlon KS, Kleinman KP, Gillman MW. Misdiagnosis of overweight and underweight children younger than 2 years of age due to length measurement bias. MedGenMed. 2005;7(4):56. https://www.medscape.com/ viewarticle/515767 [accessed 11 Nov 2020]

20. Johnson W, Cameron N, Dickson P, Emsley S, Raynor P, Seymour C, et al. The reliability of routine anthropometric data collected by health workers: a cross-sectional study. Int J Nurs Stud. 2009;46(3):310-316. https://doi.org/10.1016/j. ijnurstu.2008.10.003

21. Howe LD, Tilling K, Lawlor DA. Accuracy of height and weight data from child health records. Arch Dis Child. 2009;94(12):950-954. https://doi.org/10.1136/adc.2009.162552

22. Eckhardt CL, Eng H, Dills JL, Wisner KL. The prevalence of rapid weight gain in infancy differs by the growth reference and age interval used for evaluation. Ann Hum Biol. 2016;43(1):85-90. https://doi.org/10.3109/03014460.2014.1002533

23. Toschke AM, Grote V, Koletzko B, von Kries R. Identifying children at high risk for overweight at school entry by weight gain during the first 2 years. Arch Pediatr Adolesc Med. 2004;158(5):449452. https://doi.org/10.1001/archpedi.158.5.449

24. Bozaykut A, Paketci A, Sezer RG, Paketci C. Evaluation of risk factors for recurrent wheezing episodes. J Clin Med Res. 2013;5(5):395. https://doi.org/10.4021/jocmr1543w

25. Paranjothy S, Dunstan F, Watkins WJ, Hyatt M, Demmier JC, Lyons RA, et al. Gestational age, birth weight, and risk of respiratory hospital admission in childhood. Pediatrics. 2013;132(6):e1562-e1569. https://doi.org/10.1542/peds.2013-1737

26. Hokken-Koelega AC, De Ridder MA, Lemmen RJ, Den Hartog H, De Muinck Keizer-Schrama SM, Drop SL. Children born small for gestational age: Do they catch up? Pediatr Res. 1995;38(2): 267-271. https://doi.org/10.1203/00006450-199508000-00022

27. Sheng YJ, Xu SS, Li XJ, Lui JL, Wu XL, Xu XF. Low birth weight contributed to increased serum IL-6 levels in infantile respiratory syncytial virus infection. BMC Pediatr. 2017;17(1):205. https://doi.org/10.1186/s12887-017-0961-2

28. Krechowec S, Thompson N, Breier B. Fetal growth restriction and the developmental origins of adult disease hypothesis: experimental studies and biological consequences. In: Kiess W, Chernausek SD, Hokken-Koelega ACS, editors. Small for gestational age. Causes and Consequences, Basel: Karger Publishers; 2009. p. 26-43. https://doi.org/10.1159/000165959

29. Wheeler T, Barker DJP, O'Brien PMS, editors. Fetal programming: influences on development and disease in later life. London: RCOG Press; 1999.

30. Forno E, Han YY, Mullen J, Celedón JC. Overweight, obesity, and lung function in children and adults - a meta-analysis. $J$ Allergy Clin Immunol Pract. 2018;6(2):570-581. https://doi. org/10.1016/j.jaip.2017.07.010

31. Weinmayr G, Forastiere F, Büchele G, Jaensch A, Strachan DP, Nagel G. Overweight/obesity and respiratory and allergic 
disease in children: international study of asthma and allergies in childhood (ISAAC) phase two. PLoS One. 2014;9(12):e113996. https://doi.org/10.1371/journal.pone.0113996

32. Forno E, Weiner DJ, Mullen J, Sawicki G, Kurland G, Han YY, et al. Obesity and airway dysanapsis in children with and without asthma. Am J Respir Crit Care Med. 2014;19(3):314-323.

33. Ferrante AW, Jr. The immune cells in adipose tissue. Diabetes Obes Metab. 2013;15(s3):34-38. https://doi.org/10.1111/dom. 12154

34. Kelishadi R, Roufarshbaf M, Soheili S, Payghambarzadeh F, Masjedi M. Association of childhood obesity and the immune system: a systematic review of reviews. Child Obes. 2017;13(4):332-346. https://doi.org/10.1089/chi.2016.0176

35. Falagas ME, Kompoti M. Obesity and infection. Lancet Infect Dis. 2006;6(7):438-446. https://doi.org/10.1016/S1473-3099(06) 70523-0

36. Chen ZG, Li M, Ji JZ, Zhang Y, Chen H, Chen YF, et al. The role of serum leptin in infants with wheezing after respiratory syncytial virus infected. Zhonghua Shi Yan He Lin Chuang Bing Du Xue Za Zhi. 2009;23(1):38-40. https://doi.org/10.3760/cma. j.issn.1003-9279.2009.01.014
37. Kawamata R, Gunji Y, Ozaki A, Wakabayashi K, Miyajimaa Y, Monden $Y$, et al. Relationships between adipokine profiles, physique index, and severity of bronchiolitis in infancy. Fetal Pediatr Pathol. 2017;36(5):347-356. https://doi.org/10.1080/15 513815.2017.1332121

38. Mancuso P. Obesity and lung inflammation. J Appl Physiol (1985). 2010;108(3):722-728. https://doi.org/10.1152/japplphysiol.00781. 2009

39. Medoff BD, Okamoto $Y$, Leyton $P$, Weng $M$, Sandall $B P$, Raher MJ, et al. Adiponectin deficiency increases allergic airway inflammation and pulmonary vascular remodeling. Am J Respir Cell Mol Biol. 2009;41:397-406. https://doi.org/10.1165/ rcmb.2008-04150C

40. Duarte-Dorado DM, Madero-Orostegui DS, RodriguezMartinez CE, Nino G. Validation of a scale to assess the severity of bronchiolitis in a population of hospitalized infants. J Asthma. 2013;50(10):1056-1061. https://doi.org/10.3109/02770903.2013. 834504 